\title{
NARINGENIN PROTECTS CEREBRAL ISCHEMIC INJURY BY INHIBITING MITOCHONDRIA-MEDIATED NEURONAL APOPTOSIS IN ACUTE ISCHEMIC STROKE RATS
}

\author{
JING SHANG ${ }^{*}$, DUJUAN CAO ${ }^{1}$, ZHI CHEN ${ }^{2}$, LIJUAN SHANGGUAN ${ }^{1}$, \\ HAILONG WANG $^{1}$, XIAOPENG CUI ${ }^{2}$ and LIGUO ZHAO ${ }^{3}$
}

\author{
'Department of Neurology, Shanxi Bethune Hospital, Shanxi Academy of Medical Sciences, Taiyuan, \\ Shanxi 030032, China \\ ${ }^{2}$ Department of General Surgery, Shanxi Provincial People's Hospital, Taiyuan, \\ Shanxi 030012, China \\ ${ }^{3}$ Chongqing Zearly Bio-Tech Company Limited, Chongqing 401338, China
}

\begin{abstract}
Our study investigated the anti-neuro apoptotic effects of naringenin mediated by the mitochondria in ischemic cerebral injury due to an acute ischemic stroke in rats. Sprague-Dawley male rats were occluded in the middle cerebral artery to induce mitochondria-mediated neuronal apoptosis with acute ischemic stroke and two groups were given Naringenin $(150$ and $300 \mathrm{mg} / \mathrm{kg}$ ) orally. Neurological deficits and the infarct volume were evaluated, TUNEL staining and Western blot analysis were conducted and their results were observed. Inflammatory mediators such as TNF-á, IL-1b, IL-6, and IL-10 from the cerebellar and hypothalamic regions, cytosolic and mitochondrial protein expressions were determined and recorded. Our findings noticed a significant decrease in the infarct size, neurological score, TUNEL positive cells, cerebral IL-6, TNF-á levels, Cyt C, Bax and Bcl protein expressions, P53 levels in N-300 $(\mathrm{p}<0.01)$ group compared to the MCAO group. Cleaved caspase-3/9 protein expression decreased in N-300 group with significant changes in $\mathrm{N}-150 \mathrm{mg} / \mathrm{kg}$ group and no changes in Caspase-3/9 protein expression levels. We observed that naringenin inhibited the mitochondriamediated neuronal apoptosis in acute ischemic stroke rats, but the exact pathway of the mechanism of neuronal apoptosis is yet to be known.
\end{abstract}

Keywords: inflammatory mediators, neurological deficit, reperfusion injury, ischemic stroke

Stroke has become an evolving cause of mortality across the world with $80 \%$ ischemic stroke cases (1) with serious movements and cognitive impairments that make stroke a progressively significant social and a financial issue (2). In spite of the clinical utilization of numerous thrombolysis inhibitors, their usage is constrained due to the limited time period and undesirable outcomes or negative impacts of the therapy. Hence, the development of naturally occurring, novel, and widely used therapeutic drugs is a critical need of the hour. Decades of clinical research has established useful expertise for the treatment of cerebrovascular disorders in conventional Chinese or Indian medicine. Numerous conventional formulations commonly used for stroke in India or China or other countries have had a favorable future due to their neuropro- tective effects as well as fewer negative outcomes $(3,4)$.

Naringenin $(5,7,4$ trihydroxyflavanone) is a naturally occurring flavonoid seen in grapes and citrus plants used to treat cerebral ischemic stroke due to its antioxidant, anti-carcinogenic and anti-apoptotic effects (5). Naringenin is well known to be used as a protective agent of neurons by suppressing NK- $\kappa B$-mediated neuroinflammation in patients with an elevated risk of ischemic stroke (6).

Many therapeutic applications have been reported with anti-inflammatory action, the anti-oxidant influence of naringenin, and also its use in the treatment of cerebral ischemia and various inflammatory disorders $(7,8)$. Many herbal formulations include Resveratrol (3, 4', 5-trihydroxystilbene), Epigallocatechin-3-gallate (EGCG), etc., have been used in China or India or

* Corresponding author: e-mail: jingshang_75@hotmail.com 
Asian countries as a traditional medicine in the prevention and treatment of cardiovascular and cerebrovascular diseases, specifically stroke (9).

Research showed that naringenin can reduce the leakage of lactate dehydrogenase and the production of ROS, increase in the membrane potential of the mitochondria, thereby decreasing caspase- 3 or caspase -7 activities and preventing damage to DNA. Nevertheless, there are no reports of naringenin about its potential effects on acute ischemic stroke for its clinical and therapeutic use. Hence, the current study was intended to examine the protective effects and mechanisms of naringenin in acute ischemic stroke through cerebral ischemia / reperfusion injury in rat models. Our study helps to assess the efficacy of Naringenin in an acute ischemic stroke, which might offer certain new perspectives to prevent and treat ischemic.

\section{Materials and methods \\ Materials}

Naringenin and Triphenyltetrazolium chloride (2, 3, 5-TTC) was obtained from Sigma Alrich, China. Primary (GAPDH; Bax; Bcl-x; caspase-3) and secondary antibodies were procured from Thermo Fisher Scientific, China. ELISA kits for inflammatory mediators such as IL-6, TNF- $\alpha$ were obtained from Cell Signalling Tech, China.

\section{Animals}

Male rats (Sprague-Dawley) of ten to twelveweek-old (240-250g) were made available by Shanghai Laboratory Animal Co., at room temperature and relative humidity with free access to water and food for $12 \mathrm{hr}$ light/dark cycle and fed with a standard pellet diet was made to house the rat models. The protocol was approved to perform the experimental procedures from the Animal Ethics Committee of the Institution.

\section{MCAO model}

According to previous research, models with a brief middle cerebral artery occlusion (MCAO) were developed to induce focal cerebral ischemia (10). Isoflurane $(0.5-3 \%)$ was used to anesthetize rat models. A monofilament (3-0) having a round and sharp edge to insert into the carotid artery. The monofilament was pulled back quickly for reperfusion, post $1.5 \mathrm{~h}$ occlusion. The same surgery was performed on sham-operated rats but without MCAO.

\section{Experimental design and drug treatment}

Sixty healthy Sprague-Dawley rats were grouped into three divisions with 15 rats in each group ( $\mathrm{n}=15)$ : Sham group (I); MCAO group (II); Naringenin (150 and $300 \mathrm{mg} / \mathrm{kg}$ ) treated MCAO group (III). A single dose (150 and $300 \mathrm{mg} / \mathrm{kg}$ ) was orally administered for fifteen days prior to MCAO after dissolving naringenin in physiological saline. The group I and II received an equivalent amount of oral dose of the vehicle (physiological saline).

\section{Sample preparation}

The brain tissues (The rat's right cerebral cortexes) were suspended in $0.1 \mathrm{M}$ phosphate buffer ( $\mathrm{pH}$ 7.4; ice-cold) and homogenized. The homogenates were centrifuged at $4000 \mathrm{rpm}$ for 15 min. The supernatant was transferred into Eppendorf tubes to estimate IL-1 $\beta$, TNF- $\alpha$, and IL-6.

\section{Assessment of the deficits in the brain tissues}

The neurological deficit score was assessed based on the criteria - ' 0 ' indicated absence of deficits; 1 , indicated inability of the animal to left its forepaw completely; 2 , indicated the circling of the animal in its left direction; 3 , indicated the inability of the animal to tolerate the weight put on its left side; 4 , indicated no movements or state of unconsciousness.

\section{Assessment of infarct size}

Six animals from each group were sacrificed after conducting ischemic or reperfusion procedures followed by the immediate removal of the brain for TTC staining (11). The specimens of brain tissue were sliced serially $(2 \mathrm{~mm})$, incubated $(20 \mathrm{~min})$ in $2 \%$ Triphenyltetrazolium chloride solution, washed in phosphate buffer solution, then images were obtained using a camera (Canon, Japan). The infarct size was measured from the percent of infarct formed in the brain tissue.

\section{TUNEL staining}

A Fluorometric Device package (Promega, Wisconsin) was used to perform TUNEL staining to test apoptotic cells. Six rats from each group were given anesthesia after reperfusion for $24 \mathrm{~h}$ followed by perfusion with saline and paraformaldehyde (4\%) from the heart. The brains were extracted and inserted in paraffin. Staining was done only on the section of the $5 \mu \mathrm{m}$ thick brain tissue extracted from the cerebral cortex. The fragmented DNA from the nuclei of TUNEL-positive cells led them to emit green fluorescence and are hence known to be apoptotic. All nuclei are DAPI (Blue) counterstained. Overlay of TUNEL staining (green) and DAPI staining (blue) causes merging of images. Leica DMI8 at $488 \mathrm{~nm}$ was used to calculate five fields per section of apoptotic cells in brain tissue. 


\section{Estimation of cerebellar and hypothalamic inflammatory markers}

The standard and samples for estimating IL- $1 \mathrm{~b}$, TNF- $\alpha$ and IL- 6 were added into the wells pre-coated with their specific antibodies. The biotin-conjugated specific antibodies for IL-1b, TNF- $\alpha$ and IL-6 were added to the well, after removing the unbound materials. Horseradish Peroxidase (HRP conjugated to avidin) was added to the wells, after washing. The substrate solution is later added to the wells to give a color absorbance at $450 \mathrm{~nm}$ proportional to the amount of IL- $1 \beta$, TNF- $\alpha$ and IL- 6 .

Separation of proteins (cytosol and mitochondria)

Standard differential centrifugation was carried out using Isolation (Mitochondria) Kit (USA) for the extraction of fractions from the cytosol and mitochondria of the brain tissues. The samples of brain tissue were homogenized with the protease inhibitor cocktail in an ice-cold lysis buffer. The fractions of homogenates were subjected for centrifugation

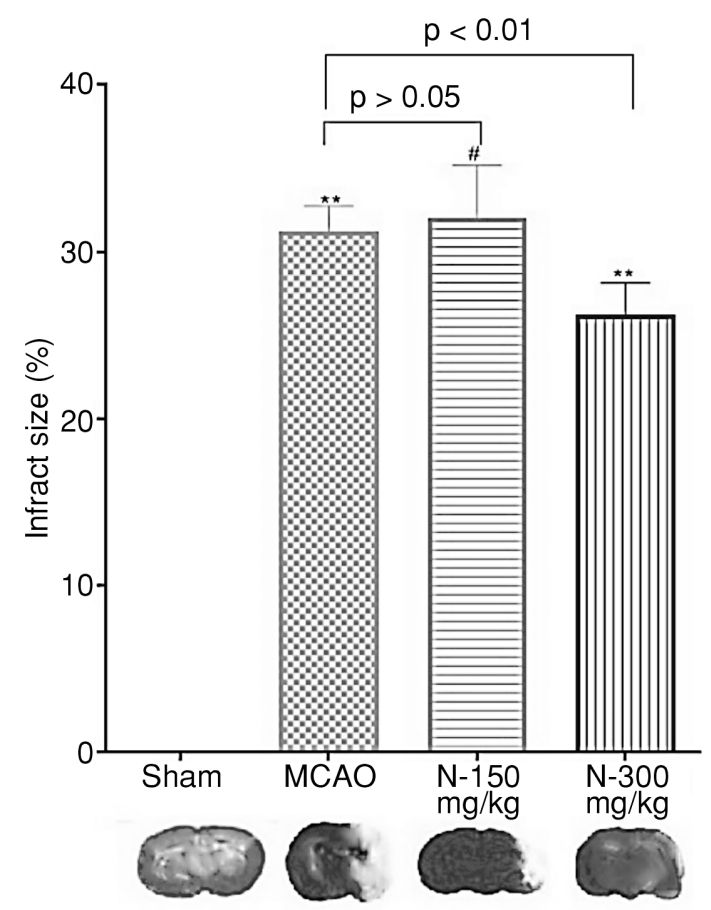

Figure 1. Effects of naringenin on infract size in rats treated at $(150 \mathrm{mg} / \mathrm{kg}$ and $300 \mathrm{mg} / \mathrm{kg}$ ) in MCAO rats.

Quantitative analysis of infract size(\%) and the representative images of 2,3,5-Triphenyletrazolium chloride (TTC) staining to demarcate middle celebral artery occlusioninduced celebral ischemia for Sham, MCAO, $\mathrm{N}-150 \mathrm{mg} / \mathrm{kg}$ and $300 \mathrm{mg} / \mathrm{kg}$ respectively. Data were presented as means \pm SEM $(n=15), * * p<0.01$ varsus Sham, ${ }^{* *} \mathrm{p}<0.01$ against $\mathrm{MCAO} ; \# \mathrm{p}>0.05$ versus MCAO. $\left(4^{\circ} \mathrm{C}\right)$ at $1000 \mathrm{~g}$ at for $5 \mathrm{~min}$; supernatants were again centrifuged at $10,000 \mathrm{~g}$ for $20 \mathrm{~min}$. The pellets thus obtained were washed three times and maintained as the mitochondrial fraction in the lysis buffer. Further centrifugation $\left(4^{\circ} \mathrm{C}\right)$ at $12,000 \mathrm{~g}$ for the supernatants at $30 \mathrm{~min}$ resulted in the cytosolic fraction of the supernatants. Brad for assay was employed to determine the concentration of the proteins of cytosol and mitochondria.

\section{Western blotting analysis (12)}

The analysis was carried out on SDS-PAGE stacked with equivalent quantities of proteins (50 $\mu \mathrm{g}$ ) following their transfer into the Polyvinylidene difluoride (PVDF) membranes charged with primary antibodies against Cyt-C, P53, Bcl-xl, Bax, caspase-3/9, cleaved-caspase-3 and GAPDH. Image J software was used to quantify bands of target proteins. For internal control, GAPHD was used.

\section{Statistical analysis}

Values were expressed as mean \pm SEM. Data analysis was done using ANOVA followed by Dunnet's t-test. A P-value of less than 0.05 was deemed to be statistically significant.

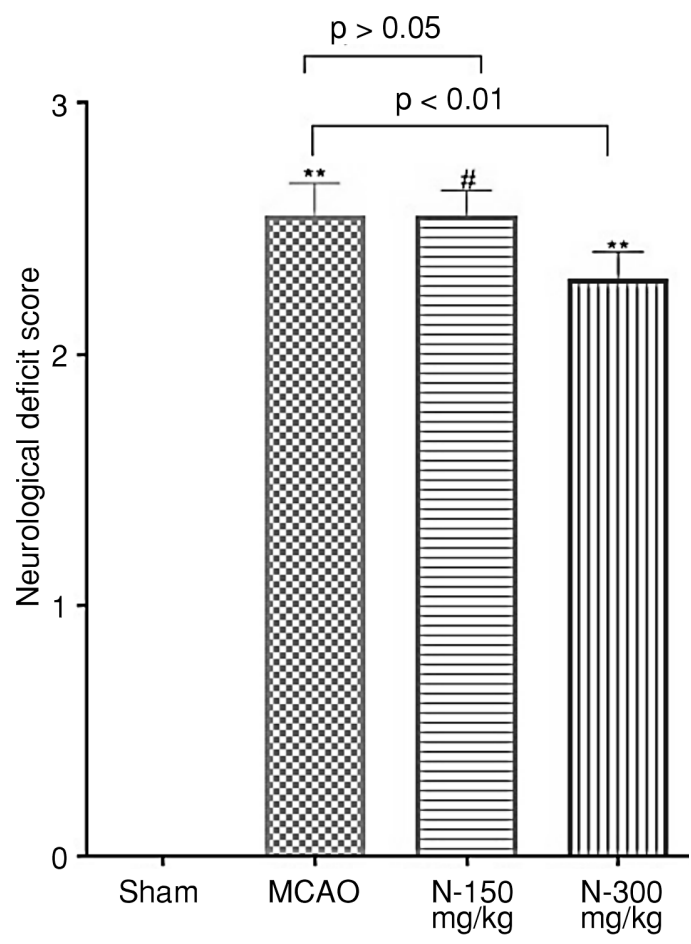

Figure 2. Effects of naringenin on neurological score in rats treated at $(150 \mathrm{mg} / \mathrm{kg}$ and $300 \mathrm{mg} / \mathrm{kg})$ in MCAO rats.

Quantitative analysis of neurological deficit scores. Data were presented as mean \pm SEM. ${ }^{* *} \mathrm{p}<0.01$ varsus Sham, ${ }^{* *} \mathrm{p}<0.01$ against MCAO; \#p > 0.05 versus MCAO. 


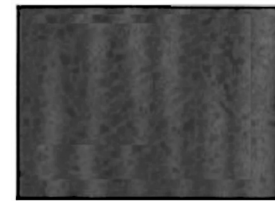

Sham

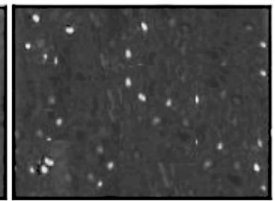

MCAO

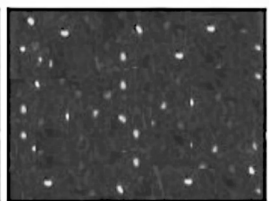

$\mathrm{N}-150$

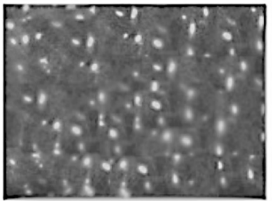

$\mathrm{N}-300$

Figure 3a. Effects of naringenin on the number of TUNEL-positive cells in MCAO rats representing TUNEL-staining brain section.

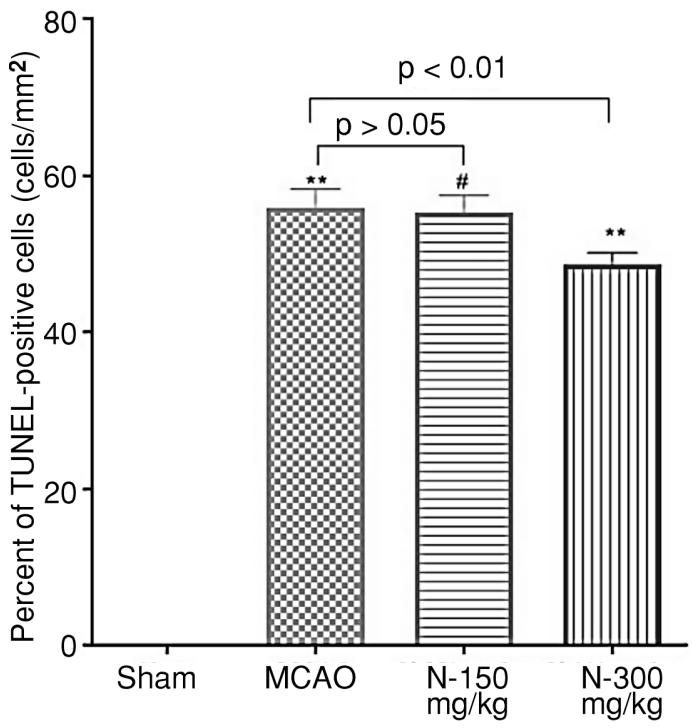

Figure $3 \mathrm{~b}$. Effects of naringenin on the number of TUNEL-positive cells in rats treated at $(150 \mathrm{mg} / \mathrm{kg}$ and $300 \mathrm{mg} / \mathrm{kg})$ in MCAO rats.

\section{RESULTS}

Effects of naringenin doses $(150 \mathrm{mg} / \mathrm{kg}$ and 300 $\mathrm{mg} / \mathrm{kg}$ ) on infarct size

The neurological deficit and infarct size were used to assess the effect of Naringenin on brain injury. The size of infarct was recorded as $31.25 \pm$ $1.49 \%$ in the MCAO group and was decreased significantly with a higher dose of naringenin (300 $\mathrm{mg} / \mathrm{kg})$ i.e., $(26.25 \pm 1.88 \%, \mathrm{p}<0.0001)$ in comparison to the MCAO group with no significant change with $150 \mathrm{mg} / \mathrm{kg}$. All these findings indicate that Naringenin reduced neurological cerebral damage in rat models having cerebral ischemia (Figure 1).

Effects of naringenin doses (150 and $300 \mathrm{mg} / \mathrm{kg}$ ) on neurological score in MCAO rats

The neurological score of rats was measured using the Bederson scale (0-3). The neurological score of animals in the N-300 group was decreased significantly from $2.55 \pm 0.13$ to $2.3 \pm 0.10$ of the MCAO group and no significant changes were observed when treated with a lower dose of naringenin $(150 \mathrm{mg} / \mathrm{kg}$; Figure 2).

\section{Effects of naringenin on apoptotic cells}

The percent of TUNEL-positive cells in the MCAO group was recorded as $56 \pm 2.34$ cells $/ \mathrm{mm}^{2}$ which was decreased significantly $(\mathrm{p}<0.04)$ in the $\mathrm{N}$ 300 group i.e., $48.75 \pm 1.43$ cells $/ \mathrm{mm}^{2}$, and no significant changes were observed in N-150 group when compared with MCAO group (Figures $3 \mathrm{a}$ and $3 \mathrm{~b}$ ).

\section{Effects of naringenin on cerebral IL-1 $\beta$ levels in} the MCAO group

The levels of cerebral IL-1b was $2.35 \pm 0.19$ $\mathrm{ng} / \mathrm{g}$ tissue in the MCAO group which were decreased significantly with a higher dose of naringenin i.e., in N-300 group (1.85 $\pm 0.03559 \mathrm{ng} / \mathrm{g}$ tissue) and no significant $(2.2 \pm 0.12 \mathrm{ng} / \mathrm{g}$ tissue; $\mathrm{p}>$ $0.05)$ changes were recorded in groups treated with a lower dose of naringenin (150 mg/kg; Figure 4).

\section{Effects of naringenin on cerebral IL-6 levels in MCAO rats}

The levels of cerebral IL-6 in the MCAO group were observed as $13.08 \pm 0.39 \mathrm{ng} / \mathrm{g}$ tissues which were decreased significantly to $7.8 \pm 0.46 \mathrm{ng} / \mathrm{g}$ tissue in the N-300 group and no significant changes were observed in the group treated with a lower dose of naringenin (150 mg/kg; Figure 5).

\section{Effects of naringenin on cerebral TNF- $\alpha$ levels in MCAO rats}

The TNF- $\alpha$ levels were increased significantly to $12.6 \pm 0.49 \mathrm{ng} / \mathrm{g}$ tissue in the MCAO group from $0.69 \pm 0.06 \mathrm{ng} / \mathrm{g}$ tissue of the sham group and decreased significantly in the $\mathrm{N}-300$ group $(8.87 \pm$ $0.78 \mathrm{ng} / \mathrm{g}$ tissue) when compared with MCAO group and no significant changes were recorded in N-150 group (Figure 6). 


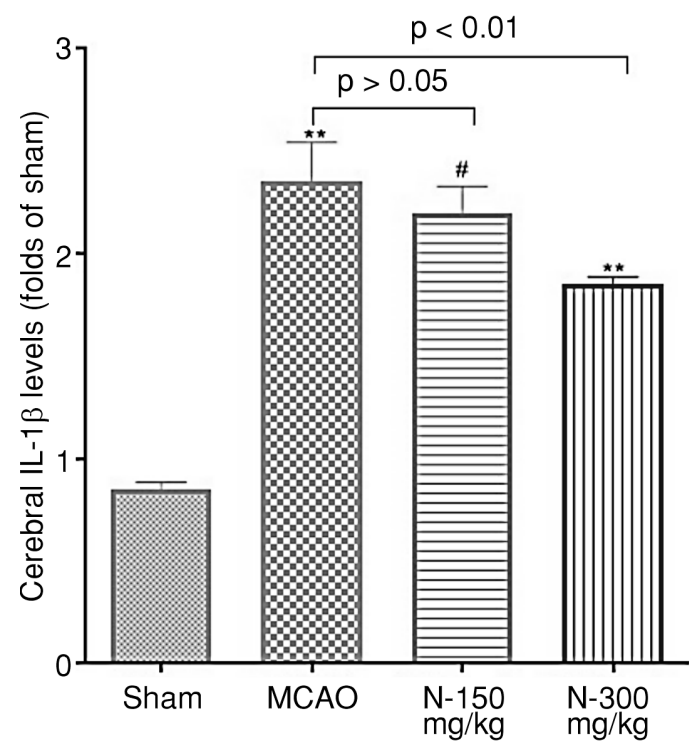

Figure 4. Effects of naringenin on celebral IL-1 $\beta$ mRNA levels in rats treated with $(150 \mathrm{mg} / \mathrm{kg}$ and $300 \mathrm{mg} / \mathrm{kg})$ in MCAO rats. Data were presented as mean \pm SEM. $* * p<0.01$ versus Sham, $* * \mathrm{p}<0.01$ against MCAO; $\# \mathrm{p}>0.05$ versus MCAO.

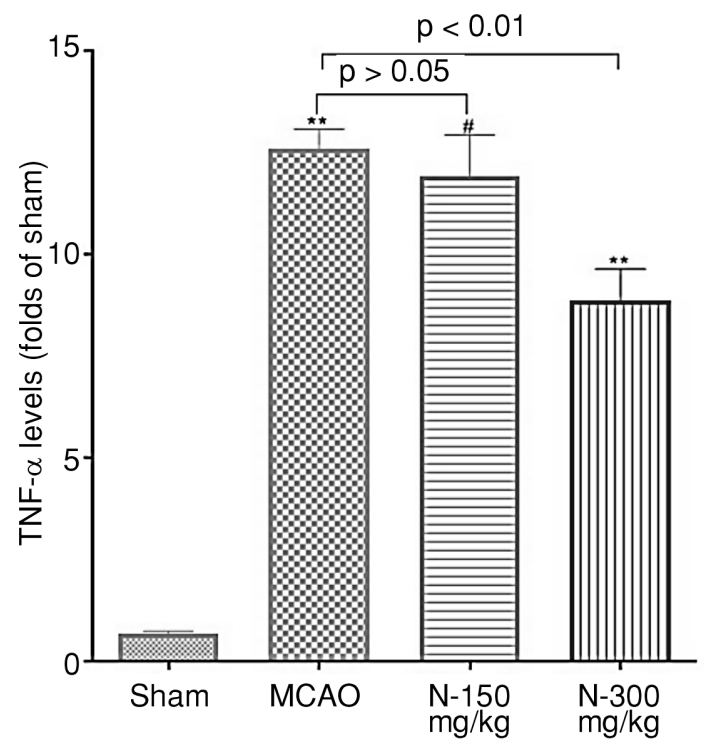

Figure 6. Effects of naringenin on celebral TNF- $\alpha$ mRNA levels in rats treated with $(150 \mathrm{mg} / \mathrm{kg}$ and $300 \mathrm{mg} / \mathrm{kg})$ in MCAO rats. Data were presented as mean \pm SEM. $* * p<0.01$ versus Sham, $* * \mathrm{p}<0.01$ against MCAO; $\# \mathrm{p}>0.05$ versus MCAO.

Effects of naringenin on Cyt $\mathrm{C}$ (mitochondrial and cytosolic $\mathrm{Cyt} \mathrm{C}$ ), Bax and Bcl protein expressions, and $\mathrm{P53}$ levels

The Cyt $\mathrm{C}$ protein expression of mitochondria in the MCAO group was suppressed significantly to

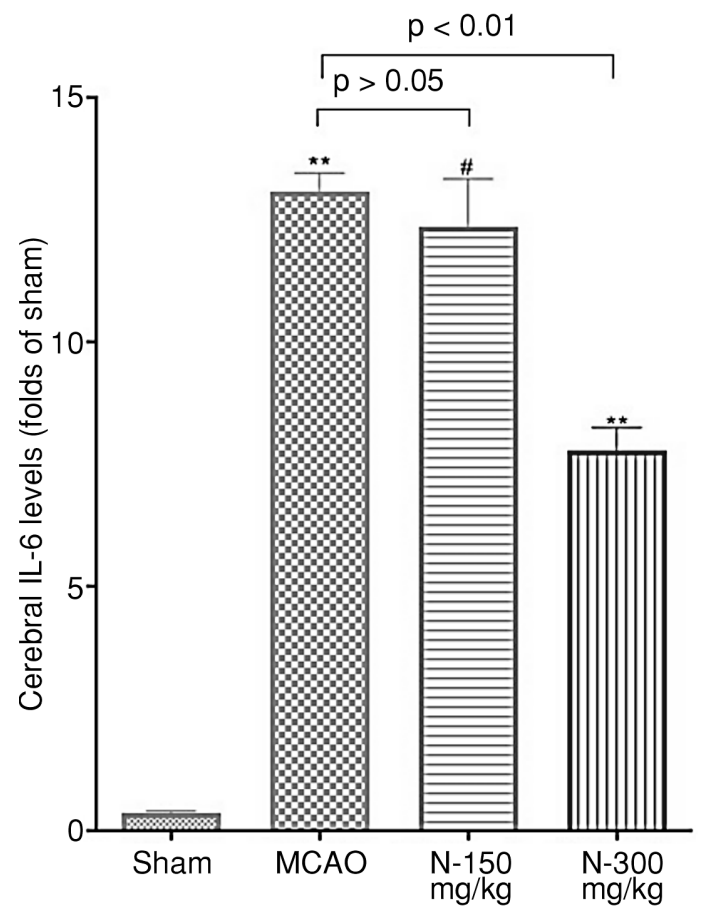

Figure 5. Effects of naringenin on celebral IL-6 mRNA levels in rats treated with $(150 \mathrm{mg} / \mathrm{kg}$ and $300 \mathrm{mg} / \mathrm{kg})$ in MCAO rats.

Data were presented as mean \pm SEM. $* * p<0.01$ versus Sham, $* * \mathrm{p}<0.01$ against MCAO; \#p $>0.05$ versus MCAO

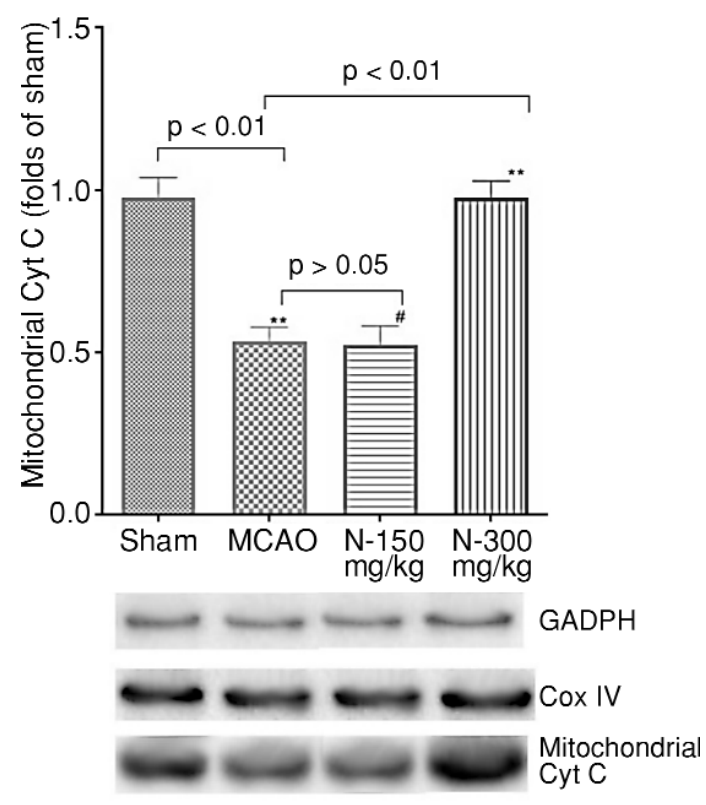

Figure 7a. Effects of naringenin on mitochondrial Cyt $\mathrm{C}$ protein expression levels in rats treated with $150 \mathrm{mg} / \mathrm{kg}$ and $300 \mathrm{mg} / \mathrm{kg}$ in MCAO rats.

Data were presented as mean \pm SEM. $* * p<0.01$ versus Sham, $* * \mathrm{p}<0.01$ against MCAO; \# $>0.05$ versus MCAO. 


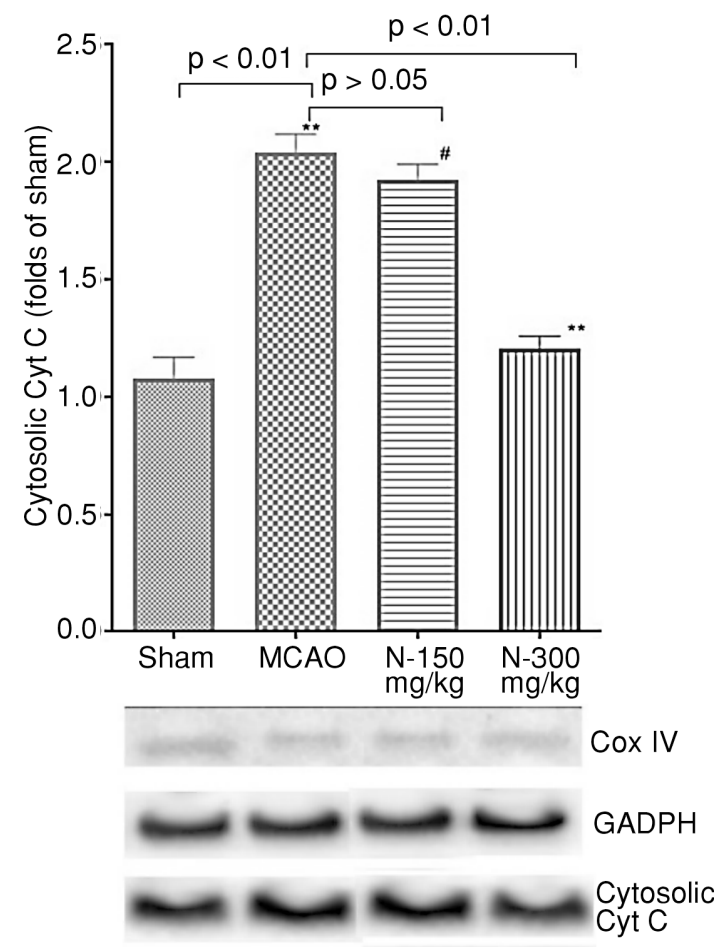

Figure 7b. Effects of naringenin on cytotolic Cyt C protein expression levels in rats treated with $150 \mathrm{mg} / \mathrm{kg}$ and $300 \mathrm{mg} / \mathrm{kg}$ in MCAO rats.

Data were presented as mean \pm SEM. $* * p<0.01$ versus Sham, ** $\mathrm{p}<0.01$ against MCAO; \#p $>0.05$ versus MCAO.

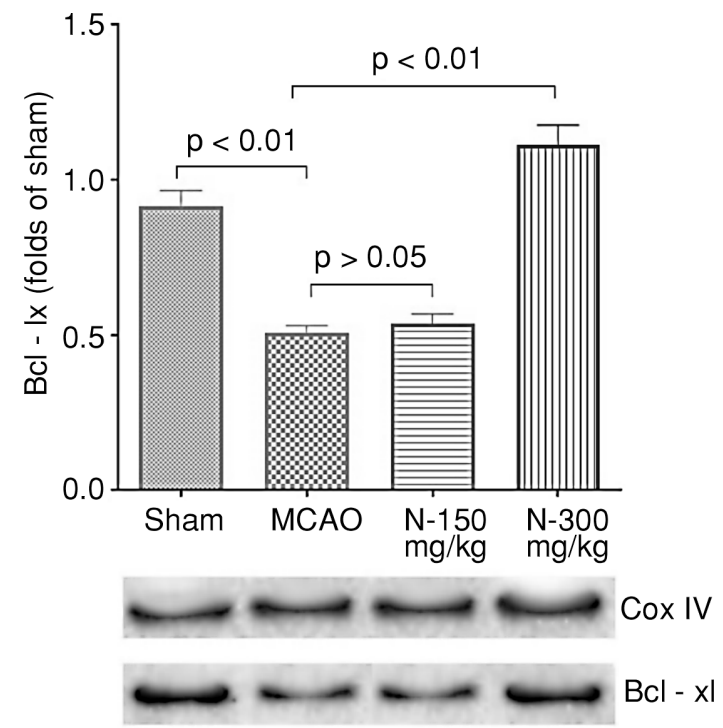

Figure 7d. Effects of naringenin on cBcl-1x expression levels in rats treated with $150 \mathrm{mg} / \mathrm{kg}$ and $300 \mathrm{mg} / \mathrm{kg}$ in MCAO rats.

Data were presented as mean \pm SEM. $* * p<0.01$ versus Sham, $* * \mathrm{p}<0.01$ against MCAO; \#p $>0.05$ versus MCAO.

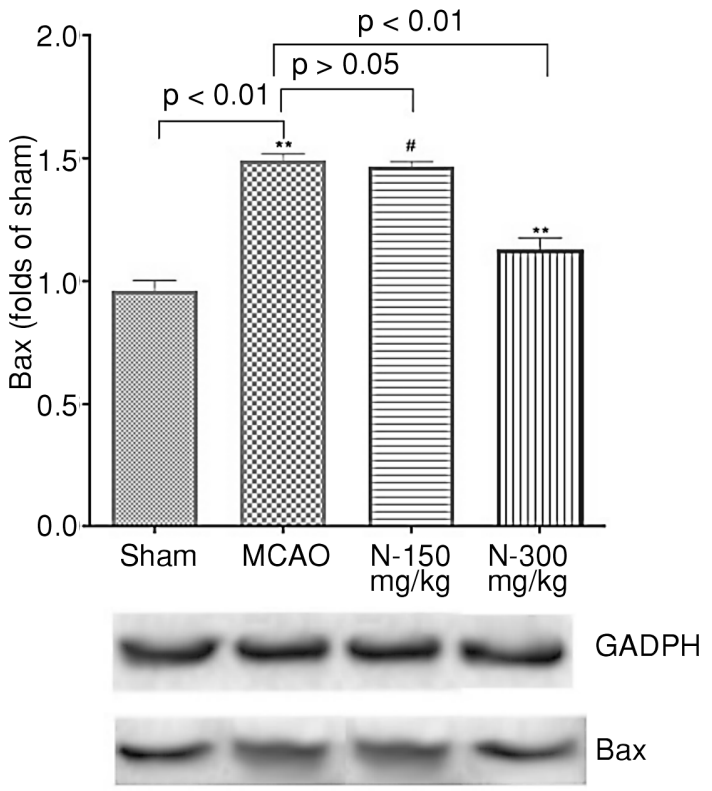

Figure 7c. Effects of naringenin on Bax protein expression levels in rats treated with $150 \mathrm{mg} / \mathrm{kg}$ and $300 \mathrm{mg} / \mathrm{kg}$ in MCAO rats.

Data were presented as mean \pm SEM. $* * p<0.01$ versus Sham, ** $\mathrm{p}<0.01$ against MCAO; \#p $>0.05$ versus MCAO.

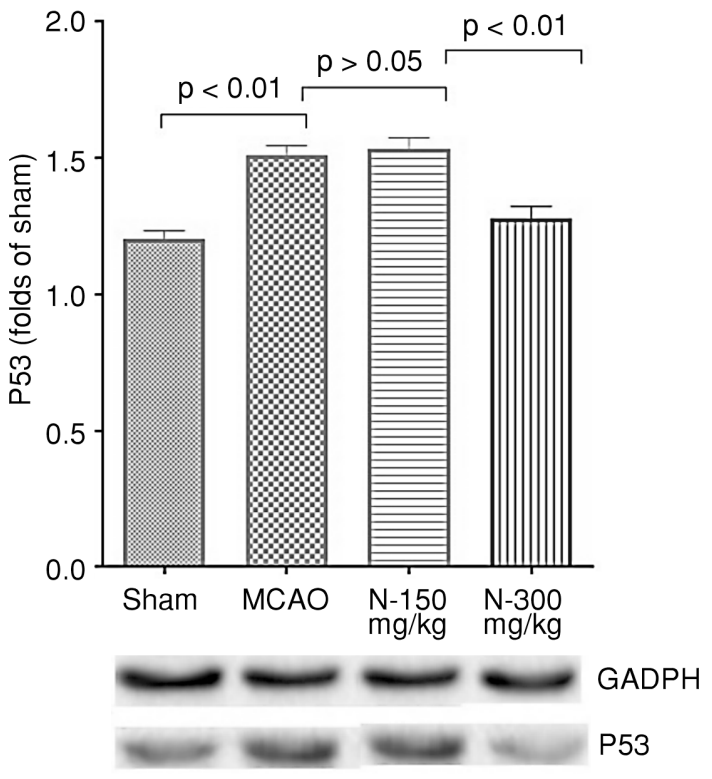

Figure 7e. Effects of naringenin on P53 expression levels in rats treated with $150 \mathrm{mg} / \mathrm{kg}$ and $300 \mathrm{mg} / \mathrm{kg}$ in MCAO rats.

Data were presented as mean \pm SEM. $* * \mathrm{p}<0.01$ versus Sham, ** $\mathrm{p}<0.01$ against MCAO; \#p $>0.05$ versus MCAO. 


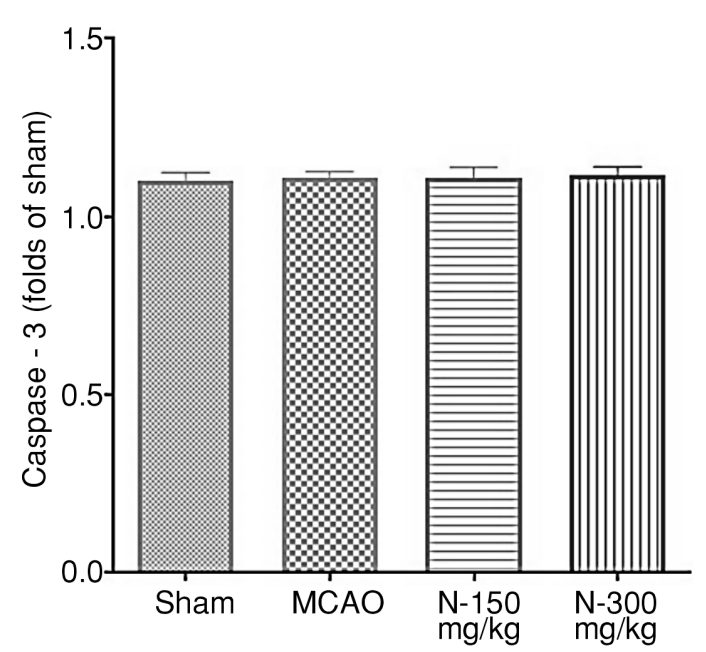

Figure 8a. Effects of naringenin on caspase-3 expression levels in rats treated with $150 \mathrm{mg} / \mathrm{kg}$ and $300 \mathrm{mg} / \mathrm{kg}$ in MCAO rats.

Data were presented as mean \pm SEM. $* * p<0.01$ versus Sham, ** $\mathrm{p}<0.01$ against MCAO; \#p $>0.05$ versus MCAO.

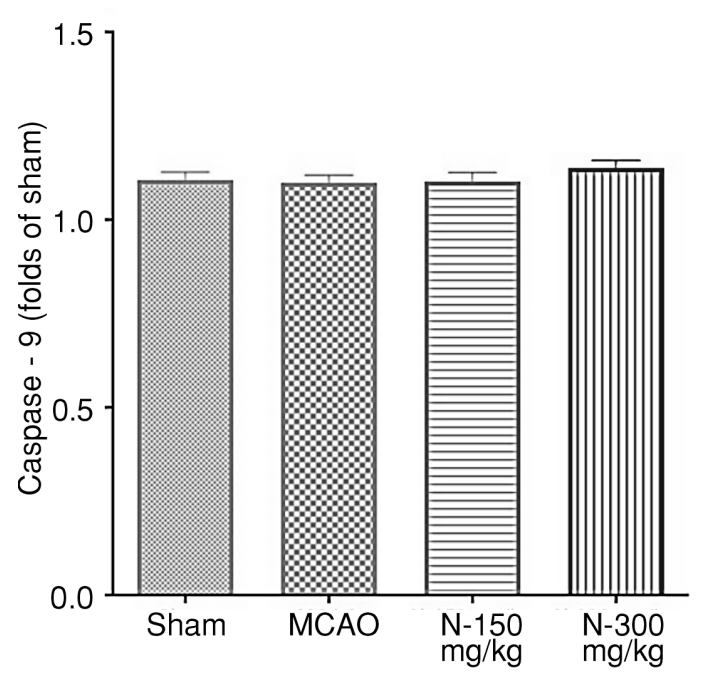

Figure 8c. Effects of naringenin on caspase-9 protein expression levels in rats treated with $150 \mathrm{mg} / \mathrm{kg}$ and $300 \mathrm{mg} / \mathrm{kg}$ in MCAO rats.

$0.53 \pm 0.043$ when compared to the sham group $(0.97 \pm 0.06)$ and the expression were increased significantly when treated with a higher dose of naringenin $(300 \mathrm{mg} / \mathrm{kg})$ i.e., $0.97 \pm 0.054$ and no significant changes were observed in N-150 group (Figure 7a). While the cytosolic Cyt $\mathrm{C}$ protein expression was observed as $2.04 \pm 0.07$ in the MCAO group and suppressed significantly in the N-300 group $(1.20 \pm 0.05)$ and no significant changes were observed in the cytosolic Cyt $\mathrm{C}$ protein expression

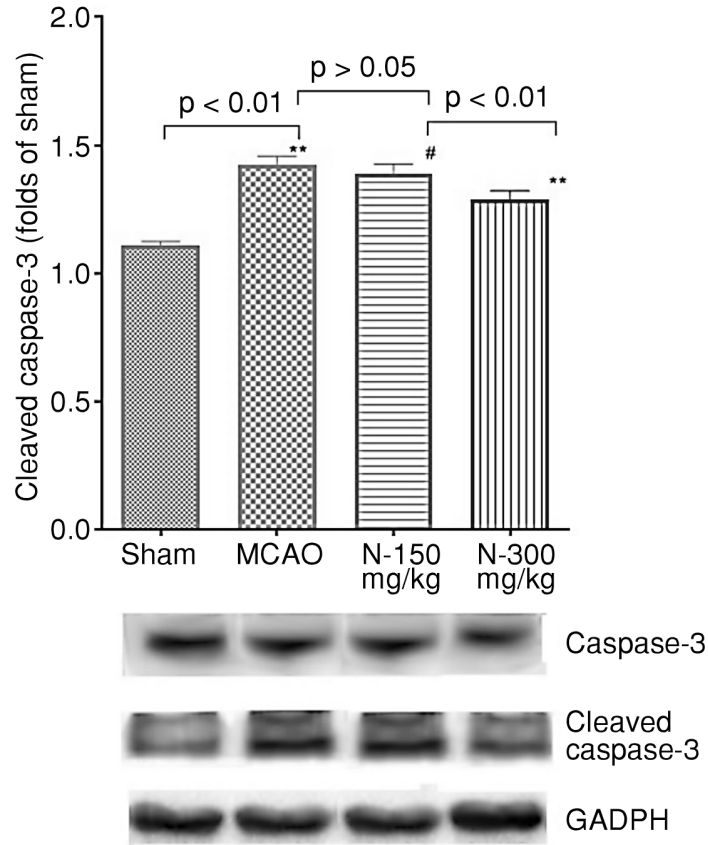

Figure $8 \mathrm{~b}$. Effects of naringenin on cleaved caspase- 3 protein expression levels in rats treated with $150 \mathrm{mg} / \mathrm{kg}$ and $300 \mathrm{mg} / \mathrm{kg}$ in MCAO rats.

Data were presented as mean \pm SEM. **p $<0.01$ versus Sham, ** $\mathrm{p}<0.01$ against MCAO; \# $>0.05$ versus MCAO.

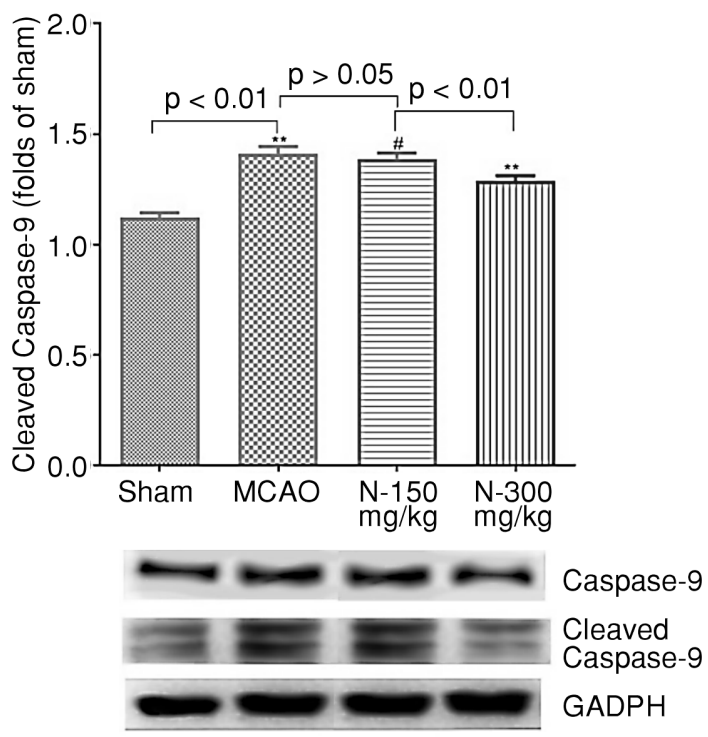

Figure 8b. Effects of naringenin on cleaved caspase- 9 protein expression levels in rats treated with $150 \mathrm{mg} / \mathrm{kg}$ and $300 \mathrm{mg} / \mathrm{kg}$ in MCAO rats.

Data were presented as mean \pm SEM. $* * p<0.01$ versus Sham, $* * \mathrm{p}<0.01$ against MCAO; \#p $>0.05$ versus MCAO. 
of N-150 group (Figure 7b). A similar trend was observed in Bax levels (Figure 7c) and $\mathrm{Bcl}$ protein expressions (Figure 7d) and P53 levels (Figure 7e).

Effects of naringenin on caspax-3, cleaved caspax-3, caspax-9 and cleaved caspax-9 expression

No significant differences were noticed in caspase-3 (Figure 8a) and caspase-9 (Figure $8 \mathrm{~b}$ ) protein expressions among the groups. However, in cleaved caspase-3 (Figure 8c) the levels were decreased significantly in the N-300 group i.e., $1.29 \pm 0.03$ when compared with the MCAO group i.e., $1.42 \pm 0.03$, and no significant changes were observed in N-150 group. A similar trend was observed in the levels of cleaved caspase-9 (Figure 8d) protein expression.

\section{DISCUSSION}

Naringenin has been used as a folk medicine for several centuries in the prevention and treatment of stroke. However, only a few preclinical studies are available in this aspect. The study findings showed that a cerebral ischemia / reperfusion injury rat model was caused by MCAO to determine naringenin's protective effects and to investigate its potential underlying mechanisms. Our findings showed that pre-treatment for 15 days with naringenin $(300 \mathrm{mg} / \mathrm{kg})$ in MCAO rats can decrease brain infarction size, boost neurological deficit, attenuate inflammatory response, restrain apoptosis of neurons and regulate mitochondria-mediated apoptotic protein expressions.

Our observations affirmed the defensive/protective effect of Naringenin against acute ischemic damage and inhibited the mitochondrial Cyt $\mathrm{C}$ which contributed to the activation of caspase- 3 and -9 which eventually led to decreased apoptotic events (13). Moreover, apoptosis is controlled by the proteins of the family $\mathrm{Bcl}-2$ by overseeing the permeability of mitochondria and releasing Cyt-C (14).

The proapoptotic protein Bax facilitates the release of Cyt $\mathrm{C}$ from mitochondria into the cytosol only when death signals are received, while this release is inhibited by the anti-apoptotic protein Bclxl. Our study showed that naringenin was able to decrease the size of brain infarction, enhance neurological deficit and repress the apoptosis of neurons in MCAO rat models, which confirms the role of naringenin as a protective agent in the ischemic stroke (15). Additionally, Naringenin modifies mitochondria-mediated apoptotic protein expression by downregulating cytosolic Cyt C, P53, Bax, cleaved caspase-3, and caspase-9, with the upregu- lation of mitochondrial Cyt $\mathrm{C}$ and $\mathrm{Bcl}-\mathrm{xl}$ levels, and no effect on caspase-3/9.

Usually, a rise in cleaved caspase-3/9levels leads to the reduction of uncleaved caspase-3/9. Our findings observed that naringenin influenced only the cleaved (caspase-3/9) and not the uncleaved (caspase-3/9) protein expressions, respectively. Though, this phenomenon has no precise explanation, so further studies are needed to be performed. All these results suggest that naringenin can enhance the brain damage caused by MCAO in rats, and the advantageous effects could be related to the apoptotic pathway mediated by mitochondria.

In addition to apoptosis, there was a rise in the evidence that showed partial involvement of inflammation in the advancement of ischemic stroke, where it was shown that the brain was infiltrated with the inflammatory mediators and cells in many animal models as well as in patients with stroke (16, 17). In an ischemic stroke, multiple mediators such as TNF- $\alpha$, IL-6 and IL- $1 \mathrm{~b}$ have been shown to be associated with inflammatory reaction $(18,19)$. Our findings showed a rise in the levels of brain mRNA expressions of TNF- $\alpha$, IL- 6 and IL- $1 \mathrm{~s} \beta$ due to MCAO. Nevertheless, the levels of these protein expressions were effectively diminished by naringenin. Hence, this study confirmed the significant anti-inflammatory effect of naringenin. However, our findings appear to have fewer limitations apart from these findings, due to the various mechanisms possible for the neuron apoptotic pathway involving endoplasmic reticulum and extrinsic apoptosis pathways.

Altogether, our study identified the role of neuronal apoptosis mediated by mitochondria and inflammation in the preventive in-vivo treatment of brain injury caused due to cerebral ischemic stroke by using naringenin. Thus, provides an experimental basis and enhances the use of naringenin in the treatment of cerebral ischemic disease.

\section{CONCLUSION}

Our novel study found the protective effects of naringenin to treat cerebral ischemic stroke by the inhibition of mitochondrial Cyt $\mathrm{C}$, thereby decreasing the occurrence of apoptotic events. Naringenin treatment also inhibited the production of inflammatory mediators, hence confirming its role as an antiinflammatory. The exact mechanism involved in the pathway of neuronal apoptosis is yet to be defined, causing a limitation to our study. Therefore, to investigate the exact pathways warrant further studies are a critical requirement. 


\section{Authors' contributions}

All authors have equally contributed to designing, writing, analysis of data and report and manuscript writing of the submitted paper.

\section{Acknowledgments}

Not applicable

\section{Conflict of interest}

The authors declare no conflict of interest.

\section{REFERENCES}

1. Moskowitz M.A., Lo E.H., Iadecola C.: Neuron 67, 181 (2010).

2. Hong K.S., Saver J.L.: Stroke 40, 3828 (2009).

3. Li F., Zhang Y, Zeng D., Xia Y., Fan X., et al.: Front. Pharmacol. 8, 21 (2017).

4. Zhang X., Shi M., Bjoras M., Wang W., Zhang G., et al.: Front. Pharmacol. 4, 152 (2013).

5. Wang K., Chen Z., Huang J., Huang L., Luo N., et al.: Clin. Exp. Pharmacol. Physiol. 44, 862 (2017).

6. Raza S.S., Khan M.M., Ahmad A., Ashafaq M., F Islam F., et al.: Neuroscience 230, 157 (2013).
7. Pharmacopoeia of the People's Republic of China, pp. 670-671, Chinese Medical Science and Technology Press, Beijing 2015.

8. Lee K.K.H, Kwong W.H, Chau F-T., Yew D.T., Chan W.Y.: Pharmacol. Toxicol. 91, 185 (2002).

9. Zhang L., Lam W.P., Lü L., Wang C., Wong Y.W., et al.: Chin. Med. 5, 35 (2010).

10. Zhang Y., Li H., Huang M., Chu K., Xu W., et al.: J. Ethnopharmacol. 158, 76 (2014).

11. Shen H., Wu X., Zhu Y., Sun H.: PLoS One 8, e57055 (2013).

12. Lai W., Zheng Z., Zhang X., Wei Y., Chu K.: Neurotox. Res. 28, 108 (2015).

13. Reed J.C.: Am. J. Pathol. 157, 1415 (2000).

14. Gross A., McDonnell J.M., Korsmeyer S.J.: Genes Dev. 13, 1899 (1999).

15. Jeong H-S., Choi H-Y., Choi T-W., Kim B-W., Kim J-H., et al.: Biol. Pharm. Bull. 31, 1686 (2008).

16. Anrather J., Iadecola C.: Neurotherapeutics 13, 661 (2016).

17. Vidale S., Consoli A., Arnaboldi M., Consoli D.: J. Clin. Neurol. 13, 1 (2017).

18. Wang H., Zhan Y., Xu L., Feuerstein G.Z., Wang X.: Stroke 32, 1020 (2001).

19. Yuqin Zhang, Shengnan Zhang, Huang Li, Mei Huang, Wei Xu, et al.: Mol. Med. Rep. 12, 988 (2015). 